\title{
Dinámicas de la "consolidación" democrática en América Latina
}

\author{
John Mill Ackerman
}

Evelina Dagnino, Alberto J. Olvera, Aldo PANFichi (coords.), 2006

\section{La disputa por la construcción democrática en América Latina}

Fondo de Cultura Económica, Centro de Investigaciones y Estudios Superiores en Antropología Social, Universidad Veracruzana, México.
E libro La disputa por la construcción democrática en América portante al debate actual sobre el desempeño de las nuevas democracias en América Latina. La democracia electoral está en crisis en la región. A pesar de la ola de transiciones experimentada durante las últimas dos décadas, en la mayoría de los gobiernos se siguen presentando problemas de ineficacia gubernamental, corrupción Latina constituye una aportación im- y "captura" del Estado por intereses particulares. Asimismo, la sistemática violación de los derechos humanos continúa de forma dramática.

Frecuentemente se dice que la solución a esta continua crisis del Estado moderno en América Latina se encuentra en la participación de la sociedad civil. Sin embargo, hay pocos esfuerzos empíricos, comparativos y científicos que busquen evaluar este supuesto en los hechos. A partir de un
JOHN MILL ACKERMAN: Instituto de Investigaciones Jurídicas, Universidad Nacional Autónoma de México, México-Distrito Federal.

ackerman@servidor.unam.mx

Desacatos, núm. 24, mayo-agosto 2007, pp. 301-302.

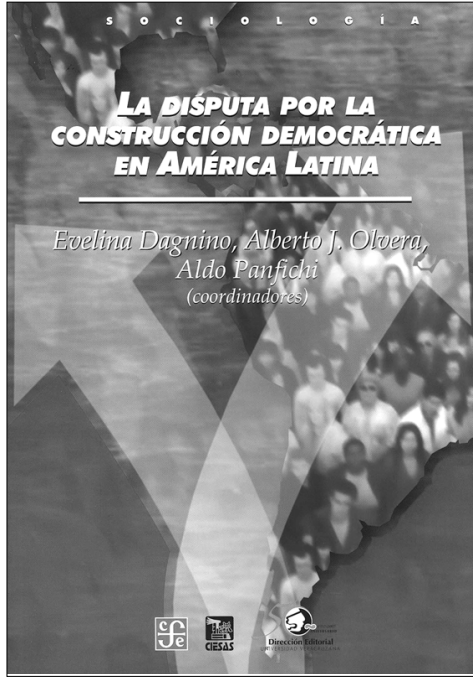

riguroso análisis de más de una docena de casos relevantes de toda la región, este libro nos demuestra la complejidad de la problemática relación entre Estado y sociedad en las sociedades latinoamericanas contemporáneas.

El libro encarna de la mejor manera la máxima gramsciana de "optimismo de la voluntad, pesimismo del intelecto". Por un lado, resume los grandes beneficios y fortalezas del "proyecto democrático-participativo" y argu- 


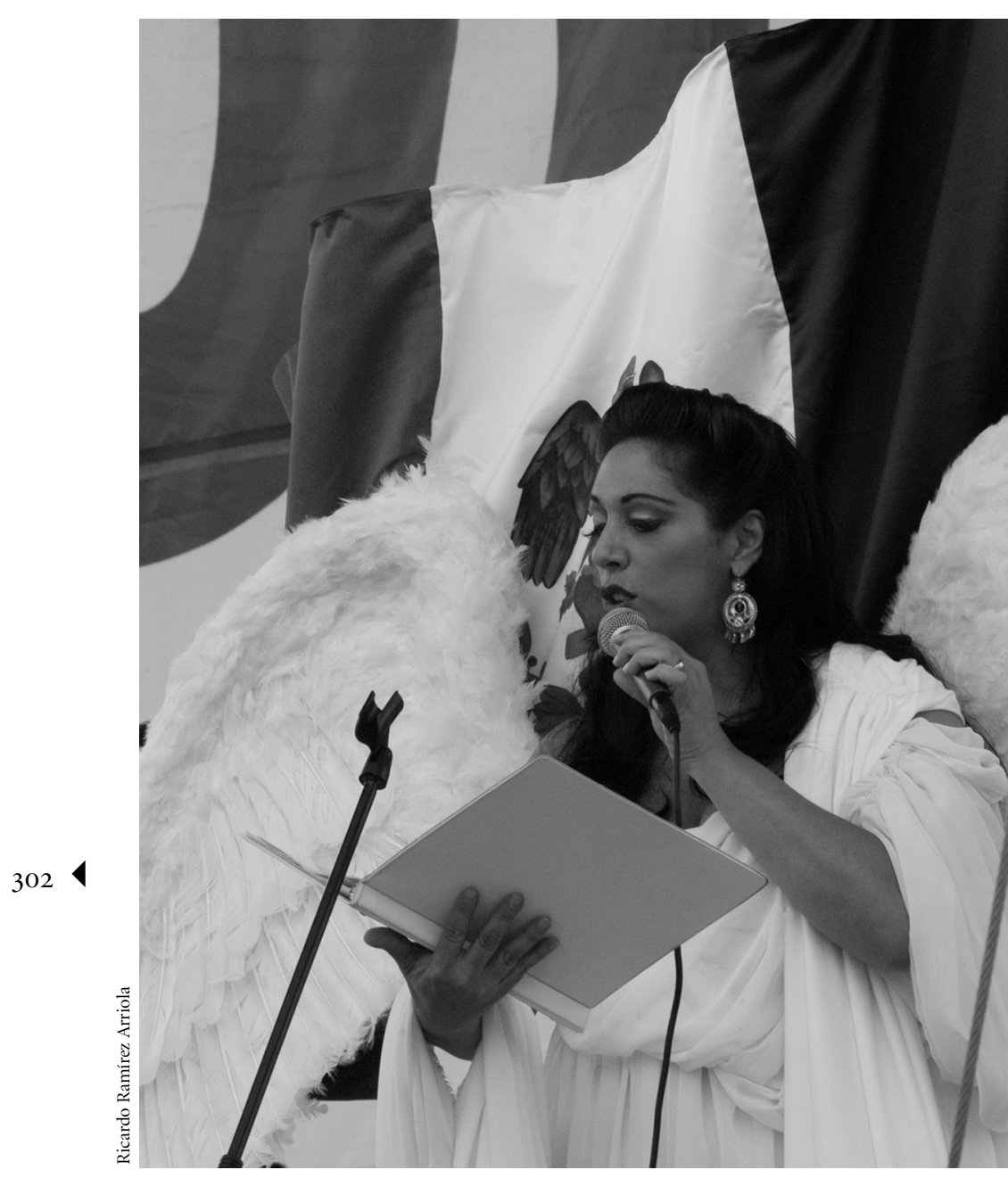

Segunda asamblea popular, Zócalo de la ciudad de México, 15 de julio de 2006.

menta que es a partir de seguir esta línea de pensamiento-práctica que América Latina podrá enfrentar los retos de la era neoliberal. Por otro lado, documenta por medio de los variados y completos estudios de caso que la lucha no es nada fácil en la práctica. Hay, por ejemplo, grandes problemas de cooptación del proyecto democráticoparticipativo por los proyectos autoritario-estatista y neoliberal. Los autores nos demuestran que el concepto y la realidad de la "sociedad civil" cobran un sentido radicalmente distinto dependiendo del proyecto en el que estén insertos.

El texto rompe con las falsas dicotomías con frecuencia establecidas entre Estado vs. sociedad, Estado vs. mercado, clases populares $v s$. élites societales. Al conceptualizar el enfrentamiento como una lucha entre "proyectos" en lugar de entre entes específicos o clases sociales, el libro nos permite acercarnos a la realidad desde una óptica multidisciplinaria y multimodal. A través de este enfoque entendemos las complejidades del proceso democrático en lugar de imponer artificialmente categorías externas que frecuentemente confunden más que esclarecen.

Vale la pena subrayar la diversidad de los casos incluidos en el libro como algo particularmente loable del texto bajo dictamen. Aquí tenemos textos sobre presupuestos participativos y movimientos indígenas, sobre la sociedad civil en el campo y en la ciudad, sobre Brasil, Perú, Argentina, Chile y México. Presenta una radiografía completa de la diversidad de esfuerzos participativos en la región y discute con sutileza e inteligencia la forma en que la sociedad civil, la sociedad política y el Estado se interrelacionan y se traslapan de manera distinta en cada contexto.

Este libro llega en un momento muy oportuno. Ya ha pasado la emoción que acompañó a las transiciones a la democracia y la etapa de la idealización de los aportes de la participación ciudadana en esta nueva época. Es la hora perfecta para una mirada sobria y fundamentada sobre las dinámicas reales de la "consolidación" democrática. Este libro constituye un parteaguas en la discusión académica sobre el tema y será también lectura obligada para los líderes sociales y gubernamentales que buscan mejorar en la práctica el impacto y el carácter democrático de la participación ciudadana.

abril de 2007 